\title{
Emotional Intelligence and Facial Affect Recognition among College Psychopaths versus Controls
}

\author{
Rebecca L. Schwartz \\ West Virginia University
}

Follow this and additional works at: https://researchrepository.wvu.edu/etd

\section{Recommended Citation}

Schwartz, Rebecca L., "Emotional Intelligence and Facial Affect Recognition among College Psychopaths versus Controls" (2010). Graduate Theses, Dissertations, and Problem Reports. 3066.

https://researchrepository.wvu.edu/etd/3066

This Thesis is protected by copyright and/or related rights. It has been brought to you by the The Research Repository @ WVU with permission from the rights-holder(s). You are free to use this Thesis in any way that is permitted by the copyright and related rights legislation that applies to your use. For other uses you must obtain permission from the rights-holder(s) directly, unless additional rights are indicated by a Creative Commons license in the record and/ or on the work itself. This Thesis has been accepted for inclusion in WVU Graduate Theses, Dissertations, and Problem Reports collection by an authorized administrator of The Research Repository @ WVU. For more information, please contact researchrepository@mail.wvu.edu. 
Emotional Intelligence and Facial Affect Recognition among College Psychopaths versus Controls

\title{
Rebecca L. Schwartz
}

\author{
Thesis submitted to the \\ Eberly College of Arts and Sciences at \\ West Virginia University \\ in partial fulfillment of the requirements for the degree of \\ Master of Science in Clinical Psychology \\ William Fremouw, Ph.D., Chair \\ Kevin Larkin, Ph.D. \\ Amy Gentzler, Ph.D. \\ Department of Psychology \\ Morgantown, West Virginia \\ 2010
}

Keywords: Psychopathy; Emotional Intelligence; Facial Affect Recognition; College Psychopath; Community Psychopath

Copyright 2010 Rebecca L. Schwartz 


\section{Abstract \\ Emotional Intelligence and Facial Affect Recognition among \\ College Psychopaths versus Controls}

\section{Rebecca L. Schwartz}

This study had two purposes: to replicate research on facial affect recognition and to test for differences in emotional intelligence abilities between a college psychopathic and controls. population. Two groups were formed based on Psychopathy Personality Inventory-Revised scores with the college psychopathic group scoring above the $75 \%$ cut off, and the controls below the $50 \%$ cut off. Forty-two college students completed questionnaires including a demographic questionnaire, the Psychopathy Personality Inventory-Revised, the Bar-On EQ-i, and the Illegal Behavior Checklist. They also completed a facial affect recognition task. There were no significant differences between the psychopathic group and the control group on their performance on the facial affect recognition task. Results indicate that the college psychopathic group was significantly lower on total emotional intelligence and four of five facets emotional intelligence subscales (as assessed by the EQ-i) and were more likely to engage in illegal behaviors. 


\section{Acknowledgements}

I would like to first and foremost thank my advisor, Bill Fremouw, for the hours of time he dedicated to helping me succeed in the completion of my thesis project.

I would also like to thank my family for supporting me in my decision to further my education in the field of Psychology.

I would like to also thank my significant other, Spencer Fix, for supporting me the past two years as I was working on my thesis project; I am particularly thankful for the support he provided me when I was struggling to write up the final portion of the project.

I would like to thank Aaron Riesbeck for designing the facial affect recognition portion of my thesis project. 
Table of Contents

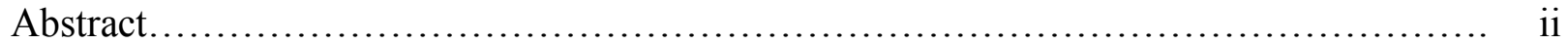

Acknowledgements....................................................... iii

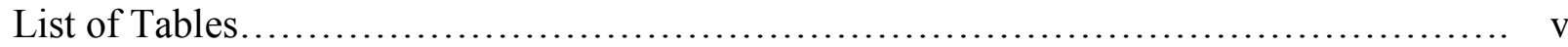

Chapter 1: Literature Review.............................................. 1

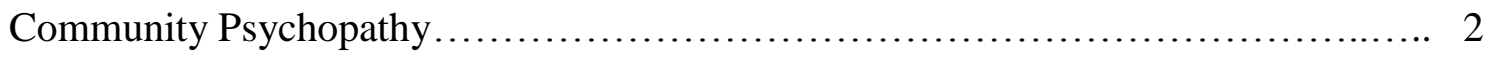

Emotion Recognition................................................. 5

Emotional Intelligence................................................ 8

Emotional Intelligence in Psychopaths.................................. 9

Psychopathy and Emotional Intelligence as an Explanation of Violent Behavior..... 10

Goals of This Study................................................. 11

Hypotheses.................................................. 11

Chapter 2: Method....................................................... 13

Participants........................................................... 13

Measures................................................................ 14

Demographic Questionnaire..................................... 14

Facial Affect Recognition........................................ 14

Psychopathic Personality Inventory - Revised....................... 14

Bar-On EQ-i................................................. 15

Illegal Behaviors Checklist........................................ 16

Procedure............................................................ 17

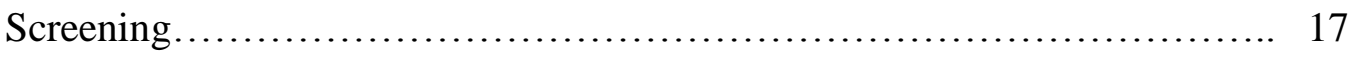

Facial Affect Recognition Task.................................. 17 
Data Analysis........................................................... 18

Chapter 3: Results..................................................... 19

Demographics.................................................... 19

Participant Illegal Behaviors.......................................... 19

Psychopathy and Facial Affect Recognition............................... 20

Psychopathy and Emotional Intelligence................................ 20

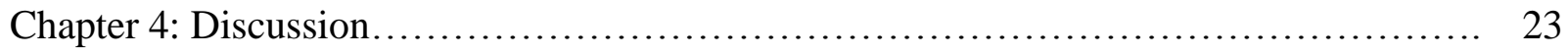

Discussion of the Results............................................ 23

Limitations....................................................... 25

Directions for Future Research........................................ 25

References................................................................... 28

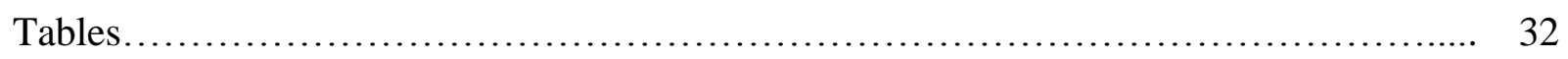

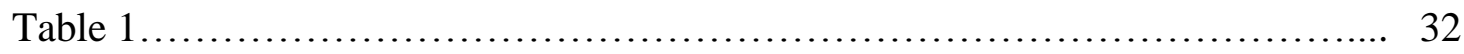

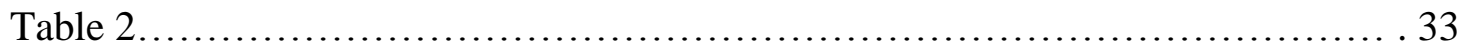

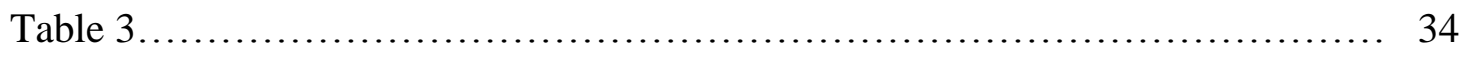

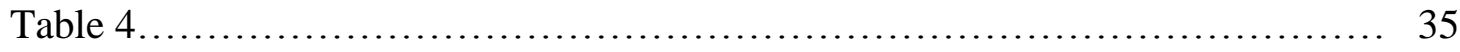

Appendices............................................................ 36

Appendix A........................................................ 36

Appendix B........................................................ 37

Appendix C........................................................ 38

Appendix D........................................................ 39

Appendix E........................................................ 40 


\section{Chapter 1: Literature Review}

\section{Psychopathy}

Psychopathy has been described throughout history by various labels such as moral insanity, mania without madness, or constitutional inferiority. Psychopathy has been characterized by a lack of remorse, callousness, and narcissism combined with antisocial and impulsive behavior. (Habel, Kühn, Salloum, Devos, \& Schneider, 2002). Research on psychopathy has primarily focused on Caucasian male prison populations; efforts have not yet been made to calculate the prevalence of psychopathy in the general public. However, epidemiologists have estimated a psychopathy incidence rate of $15-25 \%$ of males in the U.S. incarcerated population and $0.75 \%$ of males in the community. (Blair, Mitchell, \& Blair, 2005).

In his book The Mask of Sanity, Cleckley (1941) reviewed fourteen case-studies of psychopaths and discussed behaviors of a wide range of individuals (criminal to nonviolent) fitting criteria for psychopathy. According to Cleckley (1941), the only place psychopaths could readily be studied was in the criminal system, but he acknowledged there are psychopaths in the community. Cleckley described sixteen criteria for an individual to be diagnosed with psychopathy, and noted the affective deficit present in psychopaths (or lack of empathy) as the central issue.

Building upon Cleckley's work, Hare also conducted case studies, primarily focusing on the criminal population, where he researched emotional deficits in psychopaths. Hare (1980) created an assessment to measure psychopathy in adults, the Psychopathy Checklist (PCL), which later became the Psychopathy Checklist - Revised (PCL-R) (Hare, 1991). The PCL-R is an interview-based assessment that requires a review of an individual's criminal record. Analyses have found that there are two, three, or four factors derived from analyses using Hare's 
PCL-R Scale.

The two factor model indicates the Interpersonal-Affective Factor and the AntisocialImpulsivity Factor are the only factors to consider when dealing with psychopathy. The first of these, the Interpersonal-Affective Factor, involves traits such as callousness and selfishness and is associated with lack of reactivity to negative emotional stimuli. Antisocial-Impulsivity Factor is defined as an "unstable, antisocial and socially deviant lifestyle" (Hare, 1991). The three factor model posits that there are three factors of psychopathy: the Interpersonal (characterized by Machiavellian and manipulative style), the Affective (deficient emotion understanding and recognition), and the Behavioral Lifestyle Factors (antisocial lifestyle). Finally, the four factor model suggests there is one more factor to consider, beyond the three factor model, which is the Antisocial Behavior Factor (unstable, aggressive behavior). (Vitacco, 2005).

Further speculation has allowed the development of two physiological systems working in conjunction with one another to explain psychopathic tendencies: the behavioral inhibition system (BIS) and the behavioral activation system (BAS). The BIS is linked to behavioral responsiveness to punishment (typically in the form of anxiety symptoms) and is negatively correlated with psychopathy. It is related to primary psychopathy and the Interpersonal-Affective Factor (emotional detachment). The BAS is linked to reactivity to drive, fun seeking, and reward responsiveness and is positively correlated with impulsive tendencies. It is related to the Antisocial-Impulsivity Factor and secondary psychopathy. This model suggests these systems work independently from one another and together postulate a possible physiological explanation

for the concept of psychopathy (Carver \& White, 1994).

\section{Community and College Psychopaths}

Frequently the term psychopath elicits images of serial murderers or typical criminals. 
This limited scope is far from the true definition of a psychopath; psychopaths are not just criminals who might someday become incarcerated. As Cleckley (1941) noted, psychopaths can often be seen in society; most everyone has at one point in their life interacted with a psychopath. They might play a functional role in society such as a salesman, a CEO of a company, or a lawyer. Initially, research on psychopathy was limited to incarcerated populations. As this limitation was recognized, research expanded to include the general population.

There is no gold standard measurement used to differentiate between successful psychopaths and unsuccessful psychopaths, because the PCL-R, the main measure of psychopathy, is designed to be used with incarcerated psychopaths. Recent research by Kirsch, Becker, and Allen (2009) indicated that the Psychopathic Personality Inventory - Revised (PPIR) (this will be further discussed) is an effective tool for measuring psychopathy in college populations. Kirsh et al. (2009) looked at empathy in non-criminal psychopaths recruited from a college. Individuals scoring above the $87^{\text {th }}$ percentile were considered to be in the psychopathic range. There were significant differences in levels of empathy as measured by the Interpersonal Reactivity Index (a measure of dispositional empathy) between the psychopathic and the nonpsychopathic groups, and a strong negative correlation was found between measures of empathy and coldheartedness on the Psychopathy Personality Inventory- Revised (PPI-R).

Beginning the expansion of research on psychopathy into the general public, Widom (1977) recruited twenty-three male and five female subjects from the community through selfdefined means (in an advertisement). Widom used self-defined means because a measure had not yet been defined to measure psychopathy in the community population. Participants completed a clinical interview, personality questionnaires, and behavioral tasks; impulsivity and sociopathy were measured along with various personality traits. Psychopathy was determined by several 
measures: the Psychopathic Deviate $(P d)$ scale of the MMPI, an interview, a series of questionnaires including Machiavellianism and empathy scales, the Porteus Maze Test, and a delayed gratification task. Those not meeting criteria for psychopathy were rejected from the study. Through this research, Widom demonstrated certain behavioral characteristics nonincarcerated psychopaths and incarcerated psychopaths have in common, such as antisocial characteristics (e.g., substance abuse, previous arrests) and MMPI scores. In a later study designed in a similar fashion, Widom and Newman (1985) found that individuals recruited from the community scoring higher on measures that were highly correlated with psychopathy were more likely to possess personality traits consistent with those typical of psychopaths (e.g. impulsiveness, conning, and manipulativeness) (as cited in Belmore \& Quincy, 1994).

Bare, Hopko, and Armento (2004) used an undergraduate sample to observe psychopathic characteristics, anxiety, and psychophysiological responses to varying guided imagery tasks. The Self Reported Psychopathy-II was used as a measure of psychopathy (a scale created by Hare used for measuring psychopathy in noninstitutionalized psychopaths based on Hare's PCL-R), and the State-Trait Anxiety Inventory -Trait (Spielberger, Gorsuch, Lushene, Vagg, \& Jacobs, 1983) was utilized to measure anxiety. College psychopaths (undergraduate students) were classified as such if they had no past accusation or conviction of felony or misdemeanor. It was found that, using the Self Reported Psychopathy-II measure, subjects possessing higher levels of detachment displayed lower levels of skin conductance reactivity and reported lower levels of anxiety compared with participants with lower levels of detachment. This study suggested that it was not the level of deviant behavior, but the lack of emotional attachment, that related to decreased physiological reactivity in psychopaths.

In a recent study conducted by Mahmut, Homewood, and Stevenson (2008), 
undergraduate students were recruited to look at the characteristics of non-criminal psychopaths, including orbital frontal cortex dysfunction, executive functioning, and callousness. College psychopaths in this study were defined as psychopaths that were not currently arrested, although a handful of them had previous convictions. Participants were selected based on their Self Reported Psychopathy-III scale score; subjects were grouped into High Psychopathy (the top $30 \%$ of scores) and Low Psychopathy (the lowest $30 \%$ of scores). Each participant was asked to perform the Iowa Gambling Task (a task in which participants were asked to win as much "gambling money" as possible by selecting cards from multiple decks; this task was used to assess orbital frontal cortex dysfunction), the Emotional Empathy Questionnaire (to measure callousness), the National Adult Reading Test (to estimate the WAIS-R full-scale IQ score), and Part B of the Trail Making Test to further assess frontal lobe functioning. Participants high on psychopathy were found to score significantly worse on the Iowa Gambling Task due to impulsive and risk-taking behaviors, and displayed a strong lack of empathy compared with participants scoring low on psychopathy. There were no differences between groups in performance on Part B of the Trail Making Test or IQ.

\section{Emotional Recognition}

Many traits of psychopaths described by Cleckley (1941) could relate to a potential deficiency in emotional intelligence. These are: superficial charm, lack of anxiety, guiltlessness, deception and insincerity, egocentricity, poor judgment skills and an inability to learn through experience, lack of reactivity in affect, misunderstanding the repercussions of one's actions on others, and a failure to form lasting intimate relationships. It must also be noted that Cleckley's conception of the "mask of sanity" indicated certain emotional response traits in psychopaths would be intact while others would be deficient. 
Multiple facets of the human condition have been researched pertaining to emotional intelligence in psychopaths. Specifically, physiological and emotional reactivity to visual stimuli, auditory stimuli, and lexical stimuli have been observed. There have also been non-verbal studies examining emotional intelligence, which employed facial affect recognition tasks.

Kosson, Suchy, Mayer, and Libby (2002) also researched facial affect recognition in criminal psychopaths. Hare's PCL-R was used to assess for psychopathy in an inmate population. One goal of this study was to determine if there is a general emotional-processing deficit or a specific emotional-processing deficit (in failing to recognize one particular category of emotion) present in the psychopathic population. Ekman's previously validated facial affect recognition task was replicated to assess this; the presented emotions included: happy, sad, anger, disgust, surprise, and fear. To differentiate between potential hemispheric differences, half of the participants were required to use the computer mouse with their left hand while answering affect recognition questions. It was found that individuals in the psychopathic group were less able to accurately recognize disgust, and that they were surprisingly better able to recognize anger using their right hands. A left hand advantage was found for nonpsychopaths, but it was not supported that psychopaths may experience reversed lateralization (as designated by strength in facial affect recognition in their left hemisphere). However, both hemispheres of the brain could have been used with the design of this task, so this finding is notably limited.

Research conducted by Blair et al. (2004) looked at the relation between facial affect recognition and psychopathy. Inmates were recruited and assessed for psychopathy using the PCL-R. Stimuli from Ekman's facial affect recognition task (1976) were used to determine if psychopaths experienced deficits in recognizing specified emotions (happy, sad, angry, surprised, fearful, and disgusted) compared with nonpsychopaths. The facial expressions 
morphed to display varying levels of intensity of emotion. Each face went through twenty stages of $5 \%$ increments, morphing over a total of three seconds per stage. A deficit was seen in recognition of facial affect in the psychopathic group across all facial expressions. A significant difference in recognition was found, with the psychopathic group performing more poorly than the nonpsychopathic group for fearful facial expression recognition.

Hastings, Tangney, and Stuewig (2008) further examined the potential deficits of facial affect recognition in inmate psychopaths. The PCL-SV was used to differentiate between psychopathic and nonpsychopathic participants. Sixty photographs from a facial affect recognition task (Hess \& Blairy, 1995) of individuals expressing feelings of happiness, sadness, anger, fear, or shame at varying levels of intensity (60\% or $100 \%)$ were shown to participants and participants were asked to label the emotions. Findings suggested a general deficit in recognition of emotional expressions, and psychopaths had a significant deficiency in recognizing sadness. This finding did not support previous research, possibly because Hastings et al. (2008) did not use Ekman's facial recognition task (1976), which has been the primary resource for researching facial affect recognition in the majority of past research.

Iria and Fernando (2009) conducted research to further understand the deficit in recognizing fearful expressions in non-criminal versus criminal psychopaths. Subjects in this study were recruited from an employment center and a prison in Portugal. The PCL-SV was used to divide subjects into psychopaths (scores above 18) and non-psychopaths (scores below 12). Subsequently, subjects were divided into four groups: criminal psychopaths, non-criminal psychopaths, criminal non-psychopaths, and non-criminal non-psychopaths. Upon arriving at the laboratory, subjects were presented with a computer task involving viewing 56 photographs depicting fear (22), happiness (21), surprise (1), or neutral (12) facial expressions. Subjects were 
instructed to respond to each item with whether the emotion of fear was present or not in the photographs. The NimStim facial task (Tottenham et al., in press) was used for this, which was developed for research on early experience and brain development. It was found that both groups of psychopaths (criminal and non-criminal psychopaths) displayed a deficit in recognition of facial expressions with a specific deficit in recognition of fearful expressions. This suggested that psychopathy itself is likely to be related to this emotion recognition deficit.

\section{Emotional Intelligence}

Emotion serves a purpose for human beings; it allows humans to be prepared for adaptive action. This means it allows humans to recognize threats and "life sustaining" stimuli in the immediate environment (Lang, 1995, as cited in Verona et al., 2004). The study of emotional intelligence (EI) has been developed to further understand how emotion assists the human population. Similar to psychopathy, emotional intelligence has been a difficult construct to operationalize, and no single definition has been decided upon among scholars. For purposes of this research, emotional intelligence is defined as a "set of core competencies for identifying, processing, and managing emotion" (Matthews, Zeidner, \& Roberts, 2007).

EI is not fixed like the intelligence quotient (IQ); it increases with age, reaching its peak maturity in the 40s, and then it declines slightly in late life. Past research indicated one could measure emotional reactivity through physiological measurement. However, it would be much simpler and more practical to measure lack of emotional responsivity through self-report, such as a questionnaire. Several questionnaires have been designed as measures of emotional intelligence. Mixed measures of emotional intelligence (the Bar-On EQi) come from the perspective that emotional intelligence is a competency that can be learned, and are measured via self-report. Ability-based measures require participants to perform tasks relating to emotional 
intelligence including facial affect recognition and identifying which emotions fit a given situation. It has been found that mixed measures correlate with personality measures, while ability-based measures display more overlap with cognitive ability. Despite these differences, the two models have been said to be more complementary to one another than exclusive of each other. (Van Rooy, Viswesvaran, \& Pluta, 2005; Matthews et al., 2007; Mayer, Salovey, \& Caruso, 2008).

\section{Emotional Intelligence in Psychopaths}

To date, there have been two studies that have addressed emotional intelligence in nonincarcerated psychopaths using a validated measure of emotional intelligence. Vidal, Skeem, and Camp (2010) recently published a study comparing low-anxious and high-anxious psychopaths in their violent dating behavior and emotional intelligence levels. The PPI-R was used to measure psychopathy, a modified version of the Conflict Tactics Scale-2 (Straus, Hamby, Boney-McCoy, \& Sugarman, 1996) was used to measure dating violence, and the MSCEIT was used to measure emotional intelligence. One-hundred-eighty-eight male undergraduates completed these measures. Initially, using the total PPI-R score, there were no differences in emotional intelligence. Vidal et al. (2010) modified the PPI-R score by removing the anxiety scale, and, with this modified score, results indicated that individuals high on psychopathy performed more poorly on tasks related to understanding and managing emotions. Comparing the high-anxious psychopaths, low-anxious psychopaths, and low-level psychopaths on emotional intelligence scores showed a significantly lower emotional intelligence level in the high-anxious psychopaths. In particular, the high-anxious group was found to perform more poorly on managing emotions and facilitating thoughts. There was no apparent difference between low-anxious psychopaths and low-level psychopathy participants. Regarding violent 
behavior, high-anxious psychopaths were significantly more likely than low psychopathy participants to engage in violent dating behavior.

\section{Psychopathy and Emotional Intelligence as an Explanation of Violent Behavior}

Two physiological explanations were used to potentially explain deficits in emotional identification within the psychopathic population: the low-fear model, developed by Patrick (1994), and the violence inhibition model, created by Blair (1995). The low-fear model explains psychopathic emotional dysfunction as the result of a reduced ability to experience the emotion of fear. The result of this dysfunction is a diminished ability to adjust behavior when negative emotional consequences are the result of their actions. Blair's violence inhibition model (1995) posits that the brains of psychopaths have not developed in a way that allows them to recognize distress in victims. This model states that psychopaths are physiologically deficient in the area of the brain that responds to the emotions sadness and fear (namely the amygdala), the main idea being that there is no recognition of, and presumably, no aversion to another individual's fearful or saddened state. It also states that because of this deficit, psychopaths are less able to monitor their own aggressive behavior.

Psychopaths' deficiency in emotional intelligence may predispose violent behaviors in several ways, including poor conditioning, emotional detachment, and overall emotional deficiency. The inability to develop appropriate conditioned responses to aversive or negative consequences is likely to make it more difficult for psychopaths to learn to avoid the behaviors that result in negative consequences. Acts of impulsive violence are more likely to be experienced by those who are emotionally detached, such as the psychopathic population, because of the inability to understand emotions themselves. Accordingly, a state of underarousal may result in sensation seeking (Herpertz \& Sass, 2000). 
Discerning the areas of emotional intelligence in which college psychopaths are deficient would enhance research in the psychopathic and emotional intelligence realms and would allow the definition of each concept to be further solidified. Despite the research meriting a measure of emotional assessment in the psychopathic population, this has not been assessed in-depth.

\section{Goals of This Study}

This study replicated Iria and Fernando's (2009) work on facial affect recognition in noncriminal psychopaths and utilized photographs from Ekman's facial affect recognition task (1976). In addition, it was among the first studies to examine emotional intelligence in college psychopaths (CP). College psychopaths were defined by scoring above the $\left[75^{\text {th }}\right.$ percentile] on the PPI-R. The control group was defined based on self-nomination and scoring in the lower percentiles on the PPI-R (below the $50^{\text {th }}$ percentile) to assure that there were an equal number of participants in each group (Kirsch et al., 2009).

\section{Hypotheses}

1. The first purpose was to examine differences in facial affect recognition between $\mathrm{CP}$ and control groups. It was hypothesized that findings would indicate that $\mathrm{CP}$ would be less accurate than the control group on the overall facial affect recognition task (Hastings, Tangney, \& Stuewig, 2009; Iria \& Fernando, 2009). Furthermore, CP were expected to display a specific deficit in recognition of fearful facial expressions (Blair et al., 2004).

2. The second purpose was to examine differences on Total EQ and on the five subscales of emotional intelligence between $\mathrm{CP}$ and control groups. It was predicted that Total EQ would be lower in CP. One study has examined the link between emotional intelligence and psychopathy (Vidal et al., 2010). Unfortunately, their findings were limited, likely because their measure of psychopathy was modified and they used a different measure of emotional 
intelligence (the MSCEIT) than the present study. Therefore, the hypotheses regarding the relation between emotional intelligence and psychopathy are largely speculative.

a. On the Intrapersonal Subscale, CP were hypothesized to score lower than controls. Research has displayed that individuals high on psychopathy perform poorer on tasks related to understanding and managing emotions than controls (Vidal et al., 2010).

b. On the Interpersonal Subscale, it was hypothesized that CP group would be lower than the control group. This hypothesis was based on a previous study by Patrick et al. (1993) in which individuals high in antisociality experienced lower physiological reactivity to contextual emotional information, while subjects experiencing higher levels of detachment reacted less to explicit emotional information.

c. On the Stress Management Subscale, it was hypothesized that the CP group would score lower in comparison to the control group. Supporting this hypothesis, past research has found a link between psychopathy and impulsivity, sensation seeking, and the psychopath's lack of understanding emotions in others, which could possibly indicate that the predicted significantly lower Impulse Control Sub-Subscale in the psychopathic group would lower the entire stress management score (Herpertz \& Sass, 2000).

d. On the Adaptability Subscale, it was hypothesized that CP would score lower than the control group. There has been research displaying a significant difference in associative learning in psychopathic individuals, which in turn relates to problem solving (Mitchell, Fine, Richell, Newman, Lumsden, \& Blair, 2006).

e. On the General Mood Subscale, it was hypothesized that there will not be a difference in scores between groups. No existing research was found that assessed general mood in the psychopathic population. 


\section{Chapter 2: Method}

\section{Participants}

Subjects were selected based on surveys conducted on the Sona System Website, a university research website. Initially, a sample of 419 students enrolled in a large Middle Atlantic university took part in this online study. Participants were eliminated from analyses if they completed the study measures in twenty minutes or less $(N=38)$, if they identified their gender as "female" $(N=68$, participants were males, as the large majority of research on psychopathy has been conducted on male participants in the past, and some differences in scores based on gender have been found on emotional intelligence subscales), if they had an invalid PPI-R ( $N=4$, based on PPI-R validity scales), if they had an invalid EQi $(N=18$, based on response patterns or based on their answering the last item with a response less than 3), or if they did not complete the facial affect recognition task $(N=151)$. Following these selection procedures, 112 participants remained.

The sample of 112 participants was further divided into the college psychopathic (CP) and control groups based on their Total PPI-R scores. Difficulties recruiting participants to physically come in to complete the facial affect recognition task required the task to be altered. Participants were contacted to come to physically come in to participate in the lab facial affect recognition task for four months, and only five participants were successfully run through this task. This portion of the task was changed so that it could be completed on a separate website that was linked to the initial Sona System Website. The link to this second portion of the study was embedded in the online survey to deal with this problem. The partially modified task is explained below. Participants were offered extra credit in their psychology courses for participating in the task, and were given more extra credit if they completed the second portion, 
the facial affect recognition task. Participants were selected based on their Total PPI-R scores. $\mathrm{CP}(N=21)$ were at or above the $75 \%$ cut off for psychopathy $(M=61.45, S D=4.16)$, and control participants $(N=21)$ were the twenty-one lowest scoring participants (at or below the $50 \%$ cut off for psychopathy) on the Total PPI-R, $(M=36.15, S D=4.43)$. No participants were used from the in-person facial affect recognition task. Therefore, a total of 42 participants were included in all subsequent analyses in this study. See Table 1 for a description of participant demographic variables.

\section{Measures}

1. Demographic questionnaire. This is a questionnaire asking students general demographic questions. It includes questions regarding age, gender, class rank, ethnicity, marital status, and family income. (See Appendix A).

2. Facial affect recognition task. This was a task designed to assess recognition of six different emotional facial expressions depicted in photographs, including: happiness, sadness, anger, fear, surprise and disgust. These emotions have been found to be recognized across a range of differing cultures. Ten different actors (five females and five males) were chosen to display these six basic emotions, creating a set of sixty photographs. This test was administered on a website, embedded in the online questionnaire. When participants were directed to the website, Scoring of this test was based on a score of the first twenty faces, an overall possible score of sixty, and scores of ten for each of the presented emotions. The accuracy of performance on the first twenty faces was observed to test for a fatigue effect. (Ekman and Friesen, 1976).

3. Psychopathic Personality Inventory-Revised (PPI-R). This was a self-report measure of psychopathy designed particularly for a noncriminal population. This scale consisted of 154 Likert-style items that assess psychopathic personality characteristics with no explicit mention of 
antisocial or criminal behaviors. The PPI was revised (now PPI-R, 2005) in order to reduce culturally specific items and to lower its reading level. When scored, there were eight subscales: Machiavellian Egocentricity, Coldheartedness, Rebellious Nonconformity, Fearlessness, Social Influence, Blame Externalization, Carefree Nonplanfulness, and Stress Immunity. Furthermore, a global psychopathy score was derived from calculated results. The PPI-R and its subscales have been shown to be internally consistent. It has displayed good test-retest reliability and has excellent incremental validity (Lilienfeld, \& Widows, 2005; Patrick, 2006) (See Appendix B).

4. Bar-On EQ-i. This was a self-report measure of emotional intelligence, consisting of 133 items presented on a Likert rating scale. To strengthen the internal validity of the EQi scale, an inconsistency index, a positive impression scale (PI), and a negative impression scale (NI) have been designed. The inconsistency index was designed to compare similar items. PI was a score that was able to detect "feigning of enhanced emotional functioning" (Bar-On, 2008). When someone's PI score exceeds 120, it could be assumed that feigning had occurred. Some items falling on the PI included "I like everyone I meet" and "I have not told a lie in my life". The NI was a scale specifically designed to detect malingering. Similar to the PI, a score higher than 130 indicated false responding to questions. Items such as "I think I've lost my mind," "I do very weird things", and "I feel cut off from my body" were on this scale. Scoring high on this could either indicate an individual may be presenting themselves in an overly negative light, or it could suggest psychopathology.

The EQ-i has been found to be both reliable and valid for both genders of the college population (Dawda \& Hart, 2000; Livingstone \& Day, 2005). No significant differences in emotional intelligence have been found between various ethnic groups (Bar-On, 2000). On the EQ-i, test-retest reliability was found to be between .66 and .89 (Bar-On, 2000; Dawda \& Hart, 
2002). Research conducted by Livingstone and Day (2005) specifically assessed the construct and instrumental validity of the EQ-i. The results of this study indicated high levels of internal consistency on each of the five subscales (ranging from $\alpha=.85$ to .93 ), convergent validity from cognitive abilities (using the Canadian Forces Aptitude Test), and low to moderate discriminant validity when compared with the Personal Characteristics Inventory measure of personality ( $r$ s ranged from .15 to .66). This study also demonstrated that the EQ-i was moderately correlated with life satisfaction ( $r$ s ranged from .27 to .57 ), and was mildly correlated with job satisfaction ( $r$ s ranged from .17 to .29). The EQ-i was also weakly related to the MSCEIT, an ability-based measure of emotional intelligence (Brackett \& Mayer, 2003).

Scores are adjusted should an individual respond with a social desirability response set (PI) or unknowingly acknowledge they are malingering (NI). This correction factor based on the PI and NI scores lowered the score if PI was elevated and raised the score if the NI was elevated. Item 133, "I responded openly and honestly to the above sentences" played an important role in scoring data. Any mark lower than " 3 " on this item invalidated the assessment.

5. Illegal Behaviors Checklist (IBC). This was a brief self-report instrument designed to measure the number and type of illegal behaviors an individual participates in. Questions were designed to be answered with either a "yes" or "no" response. Higher scores indicated a greater number of criminal behaviors. The IBC was composed of 22 yes-no items and identified four categories of illegal behaviors: violent crimes against others, property crimes, drug crimes, and status offenses. Thus, participants were classified into four corresponding hierarchical categories of criminals: violent, property, drug, status. Furthermore, if there was a lack of indication of illegal behaviors, a participant was classified as having no criminal behavior (McCoy et al., 2006) (See Appendix D). 


\section{Procedure}

Screening. Participants were students recruited from WVU who completed a survey via SONA website. First, participants read over the Sona Cover Letter. Then, by selecting the "I agree" button, they were directed to an anonymous survey. Participants completed the following questionnaires assessing different attitudes or behaviors: a) a demographic questionnaire, b) the Psychopathy Personality Inventory - Revised (Lilienfeld, \& Widows, 2005; Patrick, 2006), c) the Bar-On EQi (Bar-On, 2008), and d) the Illegal Behaviors Checklist (McCoy et al., 2006). After this survey was completed, participants were given the option to continue on with the study and complete a facial affect recognition task.

Facial Affect Recognition Task. After completing the SONA survey, participants were provided with an optional link to a facial affect recognition task. Participants read the instructions for the facial affect task, acknowledged they read the instructions, and were asked to enter in their SONA ID number so that their research data could be matched. Sixty individual stimuli comprised of images recorded from five male and five female actors, each depicting one of six emotions (happiness, sadness, anger, fear, surprise, or disgust), were randomly presented for a duration of two seconds to participants. After viewing each photograph, participants were directed to a separate webpage to record their response with an unlimited amount of time. Following every set of ten slides viewed, participants were given the option of taking a break. The program prompted them with, "You may now take a break if you choose. Once you are ready to continue please press the continue button." Participants were asked to mark the corresponding emotional expression from a list of the six possible answers. The answer choices were displayed in identical order. No feedback was given to participants during this task (Iria et al, 2009). Each face was shown for two seconds, followed by an unlimited amount of time to 
indicate which emotion was presented from a multiple choice answer sheet of six emotions.

\section{Data Analysis}

Mean and standard deviation were calculated for demographic information for both of the groups (CP and control). A t-test was used to assess for differences between high and low scorers on psychopathy. Data were plotted and examined for skewness, kurtosis, and outliers. Mahalanobis distance and issues of multicollinearity were also examined. Two variables were significantly skewed, Ethnicity and Happiness Recognition. The Ethnicity variable was not altered, because only one case was not Caucasian, which was reported in the results section. The Happiness Recognition variable was negatively skewed, so it was first reflected and was then transformed using an inverse transformation. Multicollinearity issues were detected on the subsubscales of the EQ-i. This influenced the data analysis of the EQ-i scales so that only subscales were examined, and sub-subscales score analyses were exploratory.

The facial affect task was analyzed using a multivariate analysis of variance (MANOVA) to examine differences in performance on the task between $\mathrm{CP}$ and the control group. A twosample t-test was used for the comparison of baseline ratings of the two groups. CP were further assessed to look for specific affective recognition deficits. Effect sizes were calculated to determine the magnitude of potential differences between the groups. This was tested by a multivariate analysis of variance (MANOVA) for the six emotions presented in the recognition task (happy, sad, angry, fearful, surprised, disgusted, and on overall score). An ANOVA was conducted to examine any differences on the Total 20 and the Total Score on the facial affect recognition task.

The Bar-On EQ-i was assessed in individuals pre-separated into two different groups: CP and a control group. An analysis of variance (ANOVA) was conducted to determine if a 
difference exists between these groups on dependent measures of Total EQ, the Negative Impression Scale, and the Positive Impression Scale; effect sizes were calculated for each ANOVA. A multivariate analysis of variance (MANOVA) was run to examine differences in emotional intelligence factor scores on $\mathrm{CP}$ and the control group. Comparisons were made to examine differences in scores on each subscale: Intrapersonal, Interpersonal, Stress Management, Adaptability, and General Mood. Effect sizes were calculated to determine the magnitude of potential differences between the groups.

\section{Chapter 3: Results}

\section{Demographics}

Table 1 summarizes descriptive data for $\mathrm{CP}$ and the control group. The average participant age for $\mathrm{CP}$ was $M=20.29, S D=1.93$ years, and for controls was $M=21.14, S D=$ 2.92. The groups did not differ significantly by class rank or marital status. Participants in the CP group were mostly of European American descent $(\mathrm{N}=20,95.24 \%)$, as were participants in the control group $(\mathrm{N}=21,100.00 \%)$. It is unclear whether there were significant differences in income status between psychopaths and the control group, because six (28.57\%) of the CP did not report their income level.

\section{Participant Illegal Behaviors}

Participant illegal behavior was assessed using the IBC. A chi-square test for independence was used to determine if the categories of endorsed illegal behaviors (status, property, drug, or violent offenses) differed by group. This measure was also used to validate splitting the participants into groups (psychopaths and controls) using the PPI-R. CP (80.95\%) reported participating in more property and violent illegal behaviors than controls (33.33\%). There was a significant illegal behavior by group difference, $\chi^{2}(4, n=42)=11.59, p=.02, w=.47$ 
(see Table 2). This finding provides a behavioral validation of the splitting of the participants into psychopaths and controls.

Psychopathy and Facial Affect Recognition

It was predicted that individuals in the $\mathrm{CP}$ group would be less accurate than the control group in overall facial affect recognition. It was also predicted that the $\mathrm{CP}$ would have a specified deficit in recognizing fear. Two separate Univariate ANOVAs were conducted to compare the two groups ( $\mathrm{CP}$ and controls) in their facial affect recognition, on the first 20 presented faces and the entire set of faces (Total Recognition). A MANOVA was conducted on each of the individual emotions (happiness, surprise, fear, sadness, anger, and disgust) to compare $\mathrm{CP}$ and controls. Using an alpha level of .001 to evaluate homogeneity assumptions, the Box's M test of homogeneity of covariance was not significant $(p=.004)$. However, Levene's homogeneity of variance test was statistically significant for the Total 60 faces dependent variable $(p<.01)$. Wilks' Lambda was not significant, $F(8,32)=0.66, p=.72$, partial $\eta^{2}=.14$.

There were no significant differences found between the CP and control group on any of the individual emotions (see Table 3 for complete results). There was also no difference in the first 20 faces, $F(1,41)=1.38, p=.25$, (partial $\left.\eta^{2}=.03\right)$ or in total recognition, $F(1,41)=0.32, p$ $=.58,\left(\right.$ partial $\left.\eta^{2}=.01\right)$.

\section{Psychopathy and Emotional Intelligence}

It was hypothesized that CP would score lower on Total EQ than controls. An ANOVA was conducted to compare the two groups (CP and controls) in their Total EQ, as well as the Positive and Negative Impression Scales. Univariate ANOVAs indicated CP and controls were significantly different on Total EQ, $F(1,41)=10.95, p<.01$, partial $\eta 2=.22$. Total EQ was found to be lower in $\mathrm{CP}(M=81.62, S D=13.58)$ compared with controls $(M=94.33, S D=$ 
11.21). $\mathrm{CP}(M=126.81, S D=20.27)$ were also found to score significantly higher than controls $(M=109.05, S D=17.96)$ on Negative Impression, $F(1,41)=9.04, p=.01$, partial $\eta 2=.18$, but not on the Positive Impression Scale. These findings displayed medium effect sizes.

A MANOVA was performed on the five subscales of emotional intelligence to compare performance between CP and control groups. Using an alpha level of .001 to evaluate homogeneity assumptions, the Box's $\mathrm{M}$ test of homogeneity of covariance was not significant ( $\mathrm{p}$ $=.50)$. However, Levene's homogeneity of variance test was statistically significant for the General Mood Subscale $(\mathrm{p}<.05)$. Wilks' Lambda $(\Lambda=.43)$ was significant, $F(5,36)=9.46, \mathrm{p}<$ .001 , partial $\eta 2=.57$.

Univariate ANOVAs indicated CP and controls were significantly different in their scoring on the Interpersonal Subscale, $F(1,41)=22.60, p<.001$, partial $\eta 2=.36$. Scores on the Interpersonal Subscale was found to be lower in $\mathrm{CP}(M=83.43, S D=12.25)$ compared with controls $(M=102.76, S D=12.25)$. Results indicated that Stress Management was significantly poorer overall in CP $(M=85.76, S D=10.84)$ versus controls $(M=94.38, S D=11.05), F(1,41)$ $=6.51, p=.02,\left(\right.$ partial $\left.\eta^{2}=.14\right) . \mathrm{CP}(M=82.57, S D=11.05)$ and controls $(M=93.48, S D=$ 11.06) had significantly different performances on the Adaptability Subscale, $F(1,41)=22.60, p$ $<.001$, partial $\eta 2=.36$. For General Mood, CP $(M=86.48, S D=10.84)$ scored significantly lower than controls $(M=98.10, S D=11.30), F(1,41)=5.77, p=.02$, (partial $\left.\eta^{2}=.13\right)$. There was not a significant difference in performance on the Intrapersonal Subscales. (See Table 4 for Total EQ and Subscale analyses).

A series of exploratory MANOVAs were conducted on the fifteen sub-subscales within their respective subscale of emotional intelligence (i.e. Optimism, Happiness, and General 
Mood) to compare performance between $\mathrm{CP}$ and control groups. (See Appendix E for more complete exploratory analyses of Sub-Subscales). 


\section{Chapter 4: Discussion}

\section{Discussion of the Results}

Little research has been conducted on college students high on a trait measure of psychopathy. This study reduces the paucity of existing literature on college psychopaths. Furthermore, this study is one of the first to observe levels of emotional intelligence in individuals with psychopathy compared to a general college population. Vidal et al. (2010) were the first to research emotional intelligence in college psychopaths. They found differences, but only after adjusting the participants' psychopathy scores based on anxiety levels. This study aimed to assess for differences in emotional intelligence and facial affect recognition in individuals high in psychopathy versus those low in psychopathy, not accounting for anxiety. CP were defined by the PPI-R, similar to Vidal et al. (2010).

Facial affect recognition has never been previously researched in community psychopaths using a college population, but Iria and Fernando (2009) looked into the ability of community psychopaths to recognize fear with the NimStim facial affect task. Facial affect recognition has been found to be poorer in the criminal psychopathic population (Habel et al., 2002; Kosson et al., 2002; Blair et al., 2004; \& Hastings et al., 2008), and in the college psychopathic population (Iria \& Fernando, 2009). Even though facial affect recognition accuracy had been found to differ in the psychopathic population previously, this study's results did not support this. CP's performance on facial affect recognition was equivalent to the control group's performance. It is possible that this is a result of this task being the first task to assess facial affect recognition in the college psychopathic population. This is further discussed in the limitations section.

Emotional intelligence refers to core competencies that are used to identify, process, and manage emotions (Matthews, Seiner, \& Roberts, 2007). Total Emotional Intelligence scores 
were found to be significantly lower in the college psychopathy group compared with the control group. Also, on the Negative Impression Scale, college psychopaths were found to score significantly higher than controls. This was an unexpected, but not surprising finding, as the Negative Impression Scale is linked to individual items that may be suggestive of unusual personality or severe psychopathology. In the general population, scoring high on this scale could either suggest that an individual is misrepresenting themselves negatively, or it could suggest significant problems, as mentioned previously. Four of the five subscales on the EQi were found to be significantly different between the CP and control group. In fact, there was a deficit in the abilities of CPs overall, with the CPs often times functioning in the borderline range of emotional intelligence.

CP's scoring similarly to controls on Intrapersonal EQ suggests that intrapersonal skills may enhance success. The low scores of CP on Interpersonal EQ confirmed previous research findings supporting a lack of empathy in psychopaths, and the claim that psychopathic individuals are less likely to feel socially responsible and to have successful interpersonal relationships. (Cleckley, 1941; Blair, 2005; \& Kirsch et al., 2009). On Stress Management Subscale, CP scored lower, which indicates that group is more likely to behave in an abusive, unpredictable, and aggressive manner, may have anger management problems, and may be easily irritated. On the Adaptability Subscale, significant differences between CP and controls indicated that $\mathrm{CP}$ may be more likely to be tuned out, unrealistic, and disconnected, and use unstructured strategy when overcoming setbacks. CP's lower scores on the General Mood Subscale indicate that they are likely pessimistic, may fear the worst will happen, and may tend to feel uncertain about their future. 


\section{Limitations}

There has been one other publication comparing the emotional intelligence of psychopathic individuals with controls on a measure of emotional intelligence (Vidal et al, 2010). Thus, the present study is contributing to this paucity of literature. This presents limitations, unfortunately, in contrasting these findings with previous studies. There are five limitations when interpreting the findings of this study. First, this study recruited a male-only sample. As there may be gender differences in psychopathy, facial affect recognition, and emotional intelligence, these results have limited generalizability to the female psychopathic population. Second, the information in this study was collected through self-report. On selfreport measures, people may underreport seemingly socially undesirable behaviors, which may have affected responding on measures such as the PPI-R and the IBC. Third, the final groups were limited in size in spite of eight months of recruitment and over 400 participants.

Although the experimenter was not able to get participants to physically come in for the facial affect recognition task, participants were able to complete this task in an online format. This means that participant attention levels during the task were unclear. The facial affect task may also not have been successful due to a fatigue effect, as the task was always the final task to complete. Furthermore, this task had unclear control and incentives, which may affect participation rate and the motivation of participants to perform their "best", particularly on the facial affect recognition task.

\section{Directions for Future Research}

It is recommended that future research consider expanding its sample beyond the population examined in the present study. Future research looking at levels of emotional intelligence in an incarcerated population, in a juvenile population, in ethnic minorities, and in 
female psychopaths (both college and incarcerated) would enhance current understanding of emotional processing deficits in psychopaths. Furthermore, it would be beneficial to the research community interested in more completely understanding psychopathy if a solidified definition of a community psychopath were to be determined. It is uncertain what measure will most accurately assess psychopathy in a community sample; the PPI-R (Lilienfeld \& Widows, 2005), and Hare's PCL-SV (2004) are among the most widely cited, and validated measures thus far. It is recommended that future research employ various measures of community psychopathy to tackle this issue. Furthermore, more research comparing the validity of these measures is warranted.

Although significant differences were found between $\mathrm{CP}$ and the control group, the questionnaires are still self-report. Corroborations of illegal behaviors with arrest and conviction records would validate these items. Future research should either use these records, or should consider using other sources of information to verify self-reported behaviors, perhaps by having persons close to the participant also complete questionnaires regarding their illegal behaviors.

Even though significant results were found with a limited sample, a larger sample is encouraged in future research to obtain a clearer scope of the differences in emotional intelligence between college psychopaths and controls.

In the present study, one challenge was getting participants to physically come into the laboratory to complete an additional task. Perhaps providing participants with more clear and immediate incentives such as money would help recruit more participants successfully. This would allow the researcher to have a face-to-face direct examination of the participants during the facial affect recognition task, which would provide the researcher with a better idea of the motivation and performance of the participants during the task. 
One difficulty presented by using a newly developed construct, such as emotional intelligence, is that it is difficult to state with certainty that the measures used are actually observing what it was designed to measure. There has been debate in recent literature regarding measures of emotional intelligence and measures of personality and of cognitive ability. (Livingstone \& Day, 2005; Van Roy et al, 2005). Future research may include measures of the five factor personality traits and also a measure of cognitive ability along with measures of emotional intelligence to further validate findings.

Further recommendations for future research pertain to the development and enhanced understanding of emotional intelligence. Using an ability-based measure along with a mixed model measure would help solidify the construct of emotional intelligence, which, to date, has been described as "inadequate and overly broad" (Mayer et al., 2008). Continuing to employ tasks relevant to the construct of emotional intelligence, such as facial affect recognition, may also assist researchers in understanding the construct of emotional intelligence. 


\section{References}

Bar-On, R. (2000). Emotional and social intelligence. Insights from the emotional quotient inventory. The handbook of emotional intelligence: Theory, development assessment and application at home, school and in workplace. San Francisco, CA: Jossey-Bass.

Bar-On, R. (2008). Emotional Quotient Inventory: Higher Education (EQ-i: HEd). North Tonawanda, NY: Multi-Health Systems, Inc.

Bare, R. L., Hopko, D. R., \& Armento, M. E. A. (2004). The relation of psychopathic characteristics and anxiety in noncriminals: Physiological and cognitive responses to guided imagery. Journal of Psychopathology and Behavioral Assessment, 26(4), 225232.

Belmore, M. F., \& Quincy, V. L., (1994). Correlates of psychopathy in a noninstituational sample. Journal of Interpersonal Violence, 9, 339-349.

Blair, J., M., D., Mitchell, D., \& Blair, K. (2005). The Psychopath: Emotion and the Brain. Hoboken, NJ: Wiley-Blackwell.

Blair, R. J. R., Mitchell, D. G. V., Peschardt, K. S., Colledge, E., Leonard, R. A., Shine , J. H., Murray, L. K., Perrett, D. I. (2004). Reduced sensitivity to others' fearful expressions in psychopathic individuals. Personality and Individual Differences, 37, 1111-1122.

Blair, R. J. R., Sellars, C., Strickland, I., \& Clark, F. (1995). Emotion attributions in the psychopath. Personality and Individual Differences, 19(4), 431-437.

Brackett, M. A., \& Mayer, J. D. (2003). Convergent, discriminant, and incremental validity of competing measures of emotional intelligence. Personality and Social Psychology Bulletin, 29(9), 1147-1158.

Carver, C. S., \& White, T. L. (1994). Behavioral inhibition, behavioral activation, and affective 
responses to impending reward and punishment: The BIS/BAS scales. Journal of Personality and Social Psychology, 67(2), 319-333.

Cleckley, H. (1941). The Mask Of Sanity - An Attempt to Clarify Some Issues About the SoCalled Psychopathic Personality (5th ed.). Augusta, GA: Emily Cleckley.

Dawda, D., \& Hart, S. D. (2000). Assessing emotional intelligence: reliability and validity of the Bar-On Emotional Quotient Inventory (EQ-i) in university students. Personality and Individual Differences, 28, 797-812.

Ekman, P., \& Friesen, W. (1976). Pictures offacial affect. Palo Alto, CA: Consulting Psychologists Press.

Habel, U., Kühn, E., Salloum, J. B., Devos, H., \& Schneider, F. (2002). Emotional processing in psychopathic personality. Aggressive Behavior, 28, 394-400.

Hare, R. D. (1991). The Hare Psychopathy Checklist-Revised. North Tonawanda, NY: MultiHealth Systems.

Hastings, M. E., Tangney, J. P., \& Stuewig, J. (2008). Psychopathy and identification of facial expressions of emotion. Personality and Individual Differences, 44, 1474-1483.

Herpertz, S. C. \& Sass, H. (2000). Emotional deficiency and psychopathy. Behavioral Sciences and the Law, 18, 567-580.

Hess, U., \& Blairy, S. (1995). Set of emotional facial stimuli. Montreal, Canada: Department of Psychology, University of Quebec at Montreal.

Iria, C., \& Fernando, B. (2009). Perception of facial expressions of fear: comparative research with criminal and non-criminal psychopaths. The Journal of Forensic Psychiatry \& Psychology, 20(1), 66-73.

Kirsch, L. G., Becker, J. V., \& Allen, J. J. B. (2009). Empathy and psychopathy: The 
relationship revealed. Poster presented at APLS March, 2009

Kosson, D. S., Suchy, Y., Mayer, A. R., \& Libby, J. (2002). Facial affect recognition in criminal psychopaths. Emotion, 2(4), 390-411.

Lilienfeld, S. O., \& Widows, M. (2005). Psychopathic Personality Inventory-Revised professional manual. Lutz, FL: Psychological Assessment Resources, Inc.

Livingstone, H. A., \& Day, A. L. (2005). Comparing the construct and criterion-related validity of ability-based and mixed-model measures of emotional intelligence. Education and Psychological Measurement, 65(5),757-779.

Mahmut, M. K., Homewood, J., Stevenson, R. J. (2008). The characteristics of non-criminals with high psychopathy traits: Are they similar to criminal psychopaths? Journal of Research in Personality, 42, 679-692.

Matthews, G., Zeidner, M., \& Roberts, R. D. (2007). The Science of Emotional Intelligence: Knowns and Unknowns. New York, NY: Oxford University Press, Inc.

Mayer, J. D., Salovey, P., \& Caruso, D. R. (2008). Emotional intelligence: New ability or eclectic traits? American Psychologist, 63(6), 503-517.

McCoy, K., Fremouw, W., Tyner, E., Clegg, C., Johansson-Love, J., \& Strunk, J. (2006). Criminal-thinking styles and illegal behavior among college students: Validation of the PICTS. Journal of Forensic Science, 51(5), 1174-1177.

Mitchell, D. G. V., Fine, C., Richell, R. A., Newman, C., Lumsden, J., Blair, K. S., \& Blair, R. J. R. (2006). Instrumental learning and relearning in individuals with psychopathy and in patients with lesions involving the amygdala or orbitofrontal cortex. Neuropsychology, 20(3), 280-289.

Patrick, C. J. (2006). Handbook of Psychopathy. New York, NY: The Guilford Press. 
Patrick, C. J., Bradley, M. M., \& Lang, P. J. (1993). Emotion in the criminal psychopath: startle reflex modulation. Journal of Abnormal Psychology, 102, 82-92.

Patrick, C.J., Cuthburt, B.N., \& Lang, P.J. (1994). Emotion in the criminal psychopath: fear image processing. Journal of Abnormal Psychology, 103, 523-534.

Schutte, N. S., Malouff, J. M., Hall, L. E., Haggerty, D. J., Cooper, J. T., Golden, C. J., et al. (1998). Development and validation of a measure of emotional intelligence. Personality and Individual Differences, 25, 167-177.

Spielberger, C. D., Gorsuch, R., Lushene, R., Vagg, P. R., \& Jacobs, G. A. (1983). Manual for the State-Trait Anxiety Inventory. Palo Alto, CA: Consulting Psychologists Press.

Straus, M. A., Hamby, S. L., Boney-McCoy, S. B., \& Sugarman, D. B. (1996). The revised Conflict Tactics Scales (CTSZ): Development and preliminary psychometric data.

Tottenham, N., Tanaka, J., Leon, A. C., McCarry, T., Nurse, M., Hare, T. A., Marcus, D. J., Westerlund, A., Casey, B. J., Nelson, C.A. (in press). The NimStim set of facial expressions: judgments from untrained research participants. Psychiatry Research.

Van Rooy, D. L., Viswesvaran, C. \& Pluta, P. (2005). An evaluation of construct validity: What is this thing called emotional intelligence? Human Performance, 18(4), 445-462.

Verona, E., Patrick, C. J., Curtin, J. J., Bradley, M. M., \& Lang, P. J. (2004). Psychopathy and physiological response to emotionally evocative sounds. Journal of Abnormal Psychology, 113(1), 99-108.

Vidal, S., Skeem, J., \& Camp, J. (2010). Emotional intelligence: Painting different paths for lowanxious and high-anxious psychopathic variants. Law and Human Behavior, 34, 150-163.

Widom, C. S. (1977). A methodology for studying noninstitutionalized psychopaths. Journal of Consulting and Clinical Psychology, 45, 674-683. 
Table 1

Demographic information for psychopaths and controls.

\begin{tabular}{|c|c|c|c|c|}
\hline & \multicolumn{2}{|c|}{$\begin{array}{l}\text { Controls } \\
(N=21)\end{array}$} & \multicolumn{2}{|c|}{$\begin{array}{l}\text { Psychopaths } \\
\qquad(N=21)\end{array}$} \\
\hline & $M$ & $S D$ & $M$ & $S D$ \\
\hline Age (Years) & 20.29 & 1.93 & 21.14 & 2.92 \\
\hline Class rank & $N$ & Percent & $N$ & Percent \\
\hline Freshman & 6 & 28.57 & 3 & 14.29 \\
\hline Sophomore & 8 & 38.10 & 7 & 33.33 \\
\hline Junior & 2 & 9.52 & 3 & 14.29 \\
\hline Senior & 4 & 19.05 & 6 & 28.57 \\
\hline Other & 1 & 4.76 & 2 & 9.52 \\
\hline Marital status & $N$ & Percent & $N$ & Percent \\
\hline Married & 0 & 0.00 & 2 & 9.52 \\
\hline Single & 21 & 100.00 & 17 & 80.95 \\
\hline Other & 0 & 0.00 & 2 & 9.52 \\
\hline Ethnicity & $N$ & Percent & $N$ & Percent \\
\hline White & 21 & 100.00 & 20 & 95.24 \\
\hline Other & 0 & 0.00 & 1 & 4.76 \\
\hline Income & $N$ & Percent & $N$ & Percent \\
\hline$<20,000$ & 4 & 19.05 & 3 & 14.29 \\
\hline $21,000-40,000$ & 1 & 4.76 & 5 & 23.81 \\
\hline $41,000-60,000$ & 2 & 9.52 & 2 & 9.52 \\
\hline $61,000-80,000$ & 5 & 23.81 & 3 & 14.29 \\
\hline $81,000-100,000$ & 4 & 19.05 & 1 & 4.76 \\
\hline$>101,000$ & 4 & 19.05 & 1 & 4.76 \\
\hline Other & 1 & 4.76 & 6 & 28.57 \\
\hline
\end{tabular}


Table 2

Frequency of most severe level of illegal behaviors for psychopaths and control group.

\begin{tabular}{lcccccccc}
\hline & No Illegal & Status Only & Drug & Property & Violent & $\chi^{2}$ & $d f$ & $p$ \\
\hline $\begin{array}{l}\text { Control } \\
(N=21)\end{array}$ & $4.76 \%$ & $57.14 \%$ & $4.76 \%$ & $23.81 \%$ & $9.52 \%$ & & & \\
& $(N=1)$ & $(N=12)$ & $(N=1)$ & $(N=5)$ & $(\mathrm{N}=2)$ & & & \\
& & & & & & & \\
$\begin{array}{l}\text { Psychopaths } \\
(N=21)\end{array}$ & $4.76 \%$ & $9.52 \%$ & $4.76 \%$ & $47.62 \%$ & $33.33 \%$ & 11.59 & 4 & 0.02 \\
& $(N=1)$ & $(\mathrm{N}=2)$ & $(N=1)$ & $(\mathrm{N}=10)$ & $(\mathrm{N}=7)$ & & & \\
& & & & & & & & \\
\hline
\end{tabular}


Table 3

Facial affect recognition performance of psychopaths versus control participants.

\begin{tabular}{|c|c|c|c|c|c|c|c|}
\hline & \multicolumn{2}{|c|}{$\begin{array}{l}\text { Controls } \\
\qquad(N=21)\end{array}$} & \multicolumn{2}{|c|}{$\begin{array}{l}\text { Psychopaths } \\
\qquad(N=21)\end{array}$} & \multirow[b]{2}{*}{$F$} & \multirow[b]{2}{*}{$p$} & \multirow[b]{2}{*}{$\eta^{2}$} \\
\hline & $M$ & $S D$ & $M$ & $S D$ & & & \\
\hline Happiness & 9.76 & 0.77 & 9.81 & 0.51 & 0.06 & 0.81 & 0.001 \\
\hline Surprise & 9.30 & 0.98 & 9.00 & 1.10 & 0.81 & 0.36 & 0.02 \\
\hline Fear & 4.75 & 2.29 & 4.62 & 2.54 & 0.00 & 0.86 & 0.001 \\
\hline Sadness & 6.25 & 2.05 & 6.14 & 1.93 & 0.03 & 0.86 & 0.001 \\
\hline Anger & 7.10 & 1.59 & 7.29 & 1.68 & 0.51 & 0.72 & 0.003 \\
\hline Disgust & 5.20 & 2.69 & 5.95 & 2.64 & 0.99 & 0.37 & 0.02 \\
\hline First 20 Faces & 13.15 & 1.57 & 13.81 & 1.99 & 1.87 & 0.18 & 0.05 \\
\hline Total Recognition & 42.35 & 3.53 & 42.81 & 5.41 & 0.32 & 0.58 & 0.01 \\
\hline
\end{tabular}

Note. Each individual emotion is out of a total of 10. Reported scores are representative of raw scores. 
Table 4

Emotional intelligence in psychopaths versus controls.

\begin{tabular}{lrrrrrrr}
\hline & \multicolumn{2}{c}{$\begin{array}{c}\text { Controls } \\
(N=21)\end{array}$} & \multicolumn{2}{c}{$\begin{array}{c}\text { Psychopaths } \\
(N=21)\end{array}$} & & & \\
& $M$ & $S D$ & $M$ & $S D$ & $F$ & $p$ & $\eta^{2}$ \\
& & & & & & & \\
\hline Positive Impression & 100.29 & 11.22 & 105.19 & 10.93 & 2.06 & 0.16 & 0.05 \\
Negative Impression* & 109.05 & 17.96 & 126.81 & 20.27 & 9.04 & 0.01 & 0.18 \\
& & & & & & & \\
Total EQ* & 94.33 & 11.21 & 81.62 & 13.58 & 10.95 & 0.002 & 0.22 \\
& & & & & & & \\
Intrapersonal & 92.76 & 12.36 & 88.24 & 14.34 & 1.20 & 0.28 & 0.03 \\
Interpersonal** & 102.14 & 12.25 & 83.43 & 12.25 & 22.60 & 0.001 & 0.36 \\
Stress Management & 94.38 & 11.05 & 85.76 & 10.84 & 6.51 & 0.015 & 0.14 \\
Adaptability** & 93.48 & 11.06 & 82.57 & 11.5 & 9.81 & 0.003 & 0.20 \\
General Mood & 98.10 & 11.30 & 86.48 & 19.07 & 5.77 & 0.02 & 0.13 \\
& & & & & & & \\
\hline
\end{tabular}

Note. $*$ ANOVAs statistically significant. Interpret scores similarly to a cognitive intelligence measure. 


\section{APPENDIX A}

Demographic Questionnaire

1. What is your gender? (circle)

Male Female

2. What is your age?

3.

4. What is your Class Rank: (circle one):

Freshman Sophomore Junior Senior Graduate Other (please specify)

5. What is your race or ethnic background?

$\begin{array}{ll}\text { White } & \text { Hispanic } \\ \text { Black } & \text { American Indian or Alaskan Native } \\ \text { Asian or Pacific Islander } & \text { Other (Please describe) } \\ \text { Multiracial } & \square\end{array}$

6. What is your marital status? (circle one):

Married Single Divorced Widowed Separated

7. What is your family's annual income? (circle one):

$\begin{array}{ll}20,000 \text { or less } & 61,000-80,000 \\ 21,000-40,000 & 81,000-100,000 \\ 41,000-60,000 & 101,000 \text { or higher }\end{array}$




\section{APPENDIX B}

Psychopathic Personality Inventory - Revised Scales

\begin{tabular}{|l|l|}
\hline Psychopathic Personality Scale & Description \\
\hline Machiavellian Egocentricity & $\begin{array}{l}\text { Ruthless manipulation of others for self- } \\
\text { serving purposes }\end{array}$ \\
\hline Coldheartedness & Callousness \\
\hline Rebellious Nonconformity & Intentionally going against the norm or reality \\
\hline Fearlessness & Audacious; daring \\
\hline Social Influence & Others' thoughts and actions have no effect \\
\hline Blame Externalization & Blaming others; not taking responsibility \\
\hline Carefree Nonplanfulness & $\begin{array}{l}\text { Living in the moment; being } \text { unconcerned with } \\
\text { the future }\end{array}$ \\
\hline Stress Immunity & Lack of anxiety or reactivity to stressors \\
\hline
\end{tabular}




\section{APPENDIX C}

The EQ-i Scales and What They Assess

\begin{tabular}{|c|c|}
\hline EQ-i SCALES & The EI Competencies and Skills Assessed by Each Scale \\
\hline Intrapersonal & Self-awareness and self-expression: \\
\hline Self-Regard & To accurately perceive, understand and accept oneself. \\
\hline Emotional Self-Awareness & To be aware of and understand one's emotions. \\
\hline Assertiveness & To effectively and constructively express one's emotions and oneself. \\
\hline Independence & To be self-reliant and free of emotional dependency on others. \\
\hline Self-Actualization & To strive to achieve personal goals and actualize one's potential. \\
\hline Interpersonal & Social awareness and interpersonal relationship: \\
\hline Empathy & To be aware of and understand how others feel. \\
\hline Social Responsibility & To identify with one's social group and cooperate with others. \\
\hline Interpersonal Relationship & $\begin{array}{l}\text { To establish mutually satisfying relationships and relate well with } \\
\text { others. }\end{array}$ \\
\hline Stress Management & Emotional management and regulation: \\
\hline Stress Tolerance & To effectively and constructively manage emotions. \\
\hline Impulse Control & To effectively and constructively control emotions. \\
\hline Adaptability & Change management: \\
\hline Reality-Testing & $\begin{array}{l}\text { To objectively validate one's feelings and thinking with external } \\
\text { reality. }\end{array}$ \\
\hline Flexibility & To adapt and adjust one's feelings and thinking to new situations. \\
\hline Problem-Solving & To effectively solve problems of a personal and interpersonal nature. \\
\hline General Mood & Self-motivation: \\
\hline Optimism & To be positive and look at the brighter side of life. \\
\hline Happiness & To feel content with oneself, others and life in general. \\
\hline
\end{tabular}




\section{APPENDIX D}

Illegal Behaviors Checklist

\begin{tabular}{|l|l|}
\hline Type of Illegal Behavior & Description and Example \\
\hline Statutory & \\
\hline Drug & Status offenses (skipping school) \\
\hline Property & Crimes involving drugs (sold marijuana) \\
\hline Violent & Property crimes (shoplifted) \\
\hline & $\begin{array}{l}\text { Violent crimes committed against people (attacked someone to } \\
\text { hurt them) }\end{array}$ \\
\hline
\end{tabular}


APPENDIX E

Emotional intelligence in psychopaths versus controls.

\begin{tabular}{|l|r|c|c|c|c|c|c|}
\hline & \multicolumn{2}{|c|}{ Controls } & \multicolumn{2}{|c|}{ Psychopaths } & & & \\
\hline & $M$ & $S D$ & $M$ & $S D$ & $F$ & $p$ & $\eta^{2}$ \\
\hline Positive Impression & 100.29 & 11.22 & 105.19 & 10.93 & 2.06 & 0.16 & 0.05 \\
\hline Negative Impression & 109.05 & 17.96 & 126.81 & 20.27 & 9.04 & 0.01 & 0.18 \\
\hline & & & & & & & \\
\hline Total EQ & 94.33 & 11.21 & 81.62 & 13.58 & 10.95 & 0.002 & 0.22 \\
\hline & & & & & & & \\
\hline Intrapersonal & 92.76 & 12.36 & 88.24 & 14.34 & 1.20 & 0.29 & 0.03 \\
\hline Self Regard & 94.33 & 13.22 & 91.14 & 15.42 & 0.52 & 0.48 & 0.01 \\
\hline Emotional Self Awareness & 100.00 & 14.56 & 95.14 & 11.10 & 1.48 & 0.23 & 0.04 \\
\hline Assertiveness & 90.76 & 14.10 & 95.19 & 13.58 & 1.08 & 0.31 & 0.03 \\
\hline Independence & 83.00 & 12.38 & 88.52 & 15.62 & 1.61 & 0.21 & 0.04 \\
\hline Self Actualization* & 102.76 & 13.95 & 87.81 & 16.93 & 9.76 & 0.003 & 0.20 \\
\hline & & & & & & & \\
\hline Interpersonal* & 102.14 & 12.25 & 83.43 & 12.25 & 22.60 & 0.001 & 0.36 \\
\hline Empath** & 101.57 & 11.80 & 83.48 & 14.52 & 19.65 & 0.001 & 0.33 \\
\hline Social Responsibility* & 104.48 & 13.92 & 80.86 & 11.66 & 35.56 & 0.001 & 0.47 \\
\hline Interpersonal Rx* & 100.76 & 15.81 & 90.57 & 12.16 & 5.48 & 0.02 & 0.12 \\
\hline & & & & & & & \\
\hline Stress Management* & 94.38 & 11.05 & 85.76 & 10.84 & 6.51 & 0.015 & 0.14 \\
\hline Stress Tolerance & 92.76 & 14.06 & 87.67 & 14.88 & 1.30 & 0.26 & 0.03 \\
\hline Impulse Control* & 96.81 & 11.41 & 85.86 & 12.21 & 9.02 & 0.01 & 0.18 \\
\hline & & & & & & & \\
\hline Adaptability* & 93.48 & 11.06 & 82.57 & 11.5 & 9.81 & 0.003 & 0.20 \\
\hline Reality Testing* & 96.57 & 13.21 & 83.52 & 12.14 & 11.1 & 0.002 & 0.22 \\
\hline Flexibility & 90.33 & 13.73 & 88.62 & 12.25 & 0.18 & 0.67 & 0.01 \\
\hline Problem Solving* & 96.00 & 11.52 & 83.52 & 14.39 & 9.62 & 0.004 & 0.19 \\
\hline & & & & & & & \\
\hline General Mood* & 98.10 & 11.30 & 86.48 & 19.07 & 5.77 & 0.02 & 0.13 \\
\hline Optimism & 96.05 & 14.49 & 85.71 & 19.58 & 3.78 & 0.06 & 0.09 \\
\hline Happines* & 100.05 & 11.39 & 88.81 & 17.32 & 6.17 & 0.02 & 0.13 \\
\hline
\end{tabular}

Note. ${ }^{*}=$ statistically significant. 